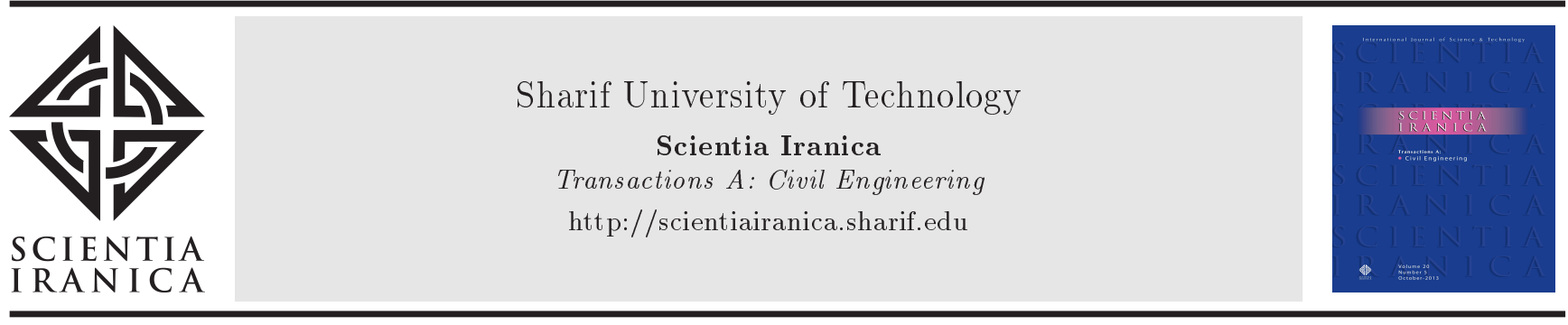

\title{
Period formula for RC frame buildings considering infill wall thickness and elasticity modulus
}

\author{
A. Koçak, M. Borekci*, and B. Zengin \\ Department of Civil Engineering, Yildiz Technical University, Istanbul, Turkey.
}

Received 11 November 2015; received in revised form 15 May 2016; accepted 6 February 2017

\section{KEYWORDS}

Period;

Infill wall thickness;

Infill wall elasticity

modulus;

RC structures;

Modal analysis.

\begin{abstract}
Estimation of a proper fundamental vibration period is an important issue in the process of the design and/or evaluation of a building. Mostly, infill walls are assumed nonstructural elements which are ignored in the estimation of the vibration period of a building in terms of stiffness. However, studies showed that infill wall has significant effect on vibration period and should be considered in the estimation of period. Even infill walls are considered by some proposed equations in the estimation of period, they do not consider the effect of infill wall stiffness. In this study, an empirical equation is proposed as a function of building height, elasticity modulus of infill wall, and thickness of infill wall. For this purpose, building periods were determined with considering different infill wall elasticity moduli, infill wall thicknesses (thus, different infill wall stiffness), and building heights. Nonlinear regression analyses were conducted with a comprehensive statistical study. Effect of elasticity modulus and thickness of infill wall on vibration period was investigated. Finally, comparisons between the proposed equation of this study and those of previous studies were conducted.
\end{abstract}

(C) 2018 Sharif University of Technology. All rights reserved.

\section{Introduction}

Buildings may suffer heavy damages under a severe earthquake; so, it is important to design a structure that guarantees life safety in such circumstances. The term life safety represents a situation where a structure undergoes significant damage without partial or total collapse with possible occurrence of injuries during the earthquake; however, the point of the term is the expectation of low life-threatening injury due to structural damage [1]. Estimating the vibration period of a structure is very important in designing a structure or evaluating an existing structure. There are two

*. Corresponding author. Tel.: +90212 3835209 E-mail addresses: akocak@yildiz.edu.tr (A. Koçak); mborekci@inm.yildiz.edu.tr (M. Borekci); zenginbasak@gmail.com (B. Zengin) common methods in seismic design of structures: forcebased and displacement-based designs. Displacementbased design is relatively new with a more complex procedure compared to force-based design. Estimation of fundamental period of a structure is a very important part of those two methods. Su et al. [2] stated that coefficient method, which is a kind of displacementbased analysis, provides good approximations for estimating the displacement demand if a proper initial vibration period is used. Besides, force-based design method traditionally is used and preferred by design engineers. Most of buildings used for housing purposes are not high-rise buildings, and the first mode of those buildings is dominant and fundamental. So, it is assumed that low-rise buildings behave as Single Degree Of Freedom (SDOF), and the first mode period of that kind of structure is very important in seismic design. Reliable earthquake loads can be estimated with more accurate first-mode (fundamental) period. The presence of masonry infill walls in RC buildings 
is very common. However, even today, during the design process of new buildings and in the assessment of the existing ones, infills are usually considered to be non-structural element, and their influence on the structural response is ignored [3,4]. It is well known that their presence modifies the structural behavior of RC structures significantly $[5,6]$. The presence of the infills is commonly associated with the significant increase in the overall structural stiffness implied by the infills, and then, a lower natural vibration period, which depends on the relevant seismic spectrum, can lead to an increase in seismic forces [3]. Considering infills as non-structural elements would lead to an unreliable evaluation of period [7]. Although there are several modelling strategies available in the literature for infills such as pinned equivalent struts macro modeling and finite-element micro modeling [8], masonry infills are generally not considered in models due to the large amount of uncertainties [9]. At the same time, the direct formulas to determinate the fundamental period of vibration generally depend on a few parameters such as height of the building, number of stories, and base length; those formulas may or may not consider the presence of infills (implicitly or explicitly) [9]. Although the effect of infill wall on period of a building is somewhat taken into account in some empirical equations in seismic codes of some countries, the infill wall thickness and infill wall elasticity module, with considerable effect on stiffness, are usually not considered in these empirical equations. Those equations, which consider infill wall effect, were not estimated considering the effect of elasticity modulus and thickness of infill wall. Fiorato et al. [10] performed dynamic analysis of a multi-story building, and showed that infill wall has considerable effect on the lateral strength and dissipated energy as well as on lateral stiffness. Zarnic and Tomazevic [11] conducted many studies on bare frame buildings and frame buildings with infill wall, and observed that the strength and stiffness of frames with infill walls are greater than those of bare frames. Based on this observation, they suggested that effect of infill wall should be considered in the design procedure. However, in cases where the effects of infill wall are not considered, infill wall should be separated by a suitable lap joint from the structural system. Goel and Chopra [12] proposed an empirical equation to estimate the fundamental vibration period of RC and steel moment-resisting frame buildings; however, they did not consider effect of infill walls. Goel and Chopra [13] proposed an improved formula by calibrating a theoretical formula for concrete shear wall buildings. Chopra and Goel [14] suggested to use $T_{L}$, which is the best-fit plus 1 standard deviation, for displacement-based assessment and $T_{U}$, which is best-fit minus 1 standard deviation, for conservative forced-based design. Panagiotakos and Fardis [15] experimentally showed that stiffness of a structure, which occurs with the position of infill walls on plan, has a great effect on seismic response of the structure. The results of an experimental study, done by AlChaar and Lamb [16] to determine the earthquake response of old buildings designed for only vertical loads without considering lateral loads, showed that the frame with infill walls has higher initial stiffness and higher strength than a bare frame. Furthermore, it was shown that span number has effects on capacity, collapse mode, and distribution of shear stress. Amanat and Hogue [17] showed that the fundamental period of an RC bare frame structure is higher than the period determined using code formulas. However, they proposed that the period obtained for a structure with infill wall is close to that which is determined according to code formulas. In their analysis, they observed that the distribution of infill wall in the structure has no considerable effect on vibration period. Instead of distribution, the total number of infill walls is important for vibration period. In these analyses, they used a constant infill wall thickness and elasticity modulus. Celep and Gencoglu [18] studied earthquake behavior of an RC frame building with infill wall. The building has weak column sections and simple geometry. They investigated the sharing of earthquake loads by columns and infill walls. Moreover, the effect of infill wall area and connection between infill wall and the beams above and below and the columns located on both sides were investigated, too. As a result, effect of infill wall increases the lateral stiffness of buildings. They stated that quality of mortar, workmanship, and high ductility level are important if beneficial effect of the infill wall is considered in the design procedure. Crowley and Pinho [19] proposed an equation for fundamental period as a function of the building heights to use in the displacement-based design method through European region. Generally, equation of fundamental period as a function of height is determined for force-based design in many codes. Budak [20] investigated the effect of infill wall on structural behavior. Fundamental period of a structure considerably decreases as a result of increasing stiffness occurred with infill walls; the first mode becomes more effective in earthquake load because of infill walls. Thus, earthquake load may increase with the effect of infill walls. Guler et al. [21] studied free vibration characteristics of the RC frame buildings, and showed that structural vibration period is effected by a nonstructural element such as infill walls. Guler et al. [22] determined the vibration period of an existing building experimentally and compared it with that estimated by a numerical model; it was observed that the results were considerably close to each other. The building was modeled with infill wall, and infill walls were implemented as virtual strut frame. They proposed 
an equation for fundamental period of a structure as a function of building height, and that equation considers the effect of infill wall. However, their equation was estimated for a constant infill wall elasticity modulus and thickness. Hatzigeorgou and Kanapitsas [7] proposed an empirical formula to estimate the fundamental period of $\mathrm{RC}$ structures considering 20 different real building configurations. They have taken into account internal and external infill walls and the soilstructure interaction effect. Oliveira and Navarro [23] measured the in-situ dynamic characteristics of 197 RC buildings in Portugal, based on ambient vibration. They obtained fundamental period as a linear function of height or number of storeys for different typologies and situations. Their numerical models reproduce the in-situ measurements with great accuracy. Panzera et al. [24] studied some reinforced concrete and masonry buildings in Catania, Italy region, considering soilstructure interaction effect, and concluded that the experimental periods obtained are always lower than those proposed by the building regulations. Ditommaso et al. [25] suggested a possible update of the code formula for the simplified estimation of the fundamental vibration period of the existing $\mathrm{RC}$ buildings, taking into account the inelastic behavior. They considered 68 buildings with different characteristics such as age, height, and damage level. Pan et al. [26] investigated the relationships between the natural vibration period and height of high-rise public residential buildings in Singapore. They considered 4 to 30 storeys' buildings. They concluded that aspect ratio of the buildings does not have significant effect on fundamental vibration period. The period-height relationships are derived using regression analysis considering the site properties of a building. According to the results of their study, the vibration periods estimated by the proposed periodheight relationship for buildings located at soft-soil site are about $40 \%$ longer than the vibration periods estimated for buildings located at firm-soil site. Many studies were conducted to investigate the effect of infill walls on structural behavior. NEHRP [27], UBC [28], EC8 [29], and TSC 2007 [30] proposed an equation to estimate fundamental vibration period of buildings as a function of building height, and some of these codes considered the effect of infill walls with a coefficient in their equation. However, thickness and elasticity modulus of infill walls are not considered in those equations of codes and studies of other researchers. In this study, an equation was proposed as a function of building height, thickness and elasticity modulus of infill walls. For this purpose, a numerical model of a building, used by Koçak and Yildirim [31], was performed in SAP 2000 with the combinations of different building heights, thicknesses and elasticity moduli of infill walls. For 9 different story numbers, 6 different elasticity moduli of infill wall, and 5 different infill wall thicknesses, 270 different buildings were modeled, and fundamental periods of these buildings were determined. Regression analysis was conducted using the results of the numerical solutions of buildings, and an equation was proposed which is a function of building height, elasticity modulus of infill wall, and thickness of infill wall.

\section{The structure and analysis}

In this study, different $\mathrm{RC}$ buildings were designed to propose an equation for the estimation of fundamental period which considers the effect of infill walls with different elasticity moduli and thicknesses. Koçak and Yildirim [31] used RC frame building with 4 spans in one direction and 5 spans in the other direction. The lengths of the building span are $5 \mathrm{~m}$ and $6 \mathrm{~m}$ in short and long directions, respectively. Storey height of the building is $3 \mathrm{~m}$. The building plan used by Koçak and Yildirim [31] in their study was considered in this study, too. $3,4,5,6,7,8,9,10$, and 11 storeys were taken into account. Column and beam dimensions were designed separately for buildings with different storey heights. Plan view of the buildings is given in Figure 1 .

In this study, infill walls were modeled as equivalent virtual strut frame elements hinged at both of the edges. Polyakov [32] was the first to study the behavior of frames with infill walls. Al-Chaar and Lamb [16] showed that infill walls' lock-in frames with equivalent virtual strut frames and stresses of frame are transferred to compressive region of frame-infill wall interface. Infill walls have the exact axial stiffness recommended by Ersin [33] and Guler et al. [22]. Axial stiffness of the equivalent virtual strut frames was determined according to the following equation:

$$
\mathrm{EA}=E \cdot t \cdot \alpha \cdot L_{d} \cdot \beta \cdot \gamma \cdot
$$

In Eq. (1), $E$ is elasticity module, $t$ is thickness, $L_{d}$ is diagonal length, $\beta$ is coefficient for taking into account opening ratio, and $\gamma$ is coefficient for taking into account all the other effects of infill walls. $\alpha$ is coefficient of the definition of equivalent frame element's efficient width compared to equivalent frame element's length. In this study, opening ratio of infill walls was not considered, and it is assumed that $\beta=1$, meaning that there is no opening on the wall.

Elasticity moduli of infill walls were assumed based on the experimental study of Ersin [33]. The considered elasticity moduli and thicknesses of infill walls are given in Table 1.

Table 1. The considered elasticity modulus and thicknesses of infill wall.

\begin{tabular}{cc}
\hline $\boldsymbol{E}(\mathbf{M P a})$ & $2500-3500-4200-4600-6000-7800$ \\
$\boldsymbol{t}(\mathbf{m m})$ & $100-150-200-250-300$ \\
\hline
\end{tabular}




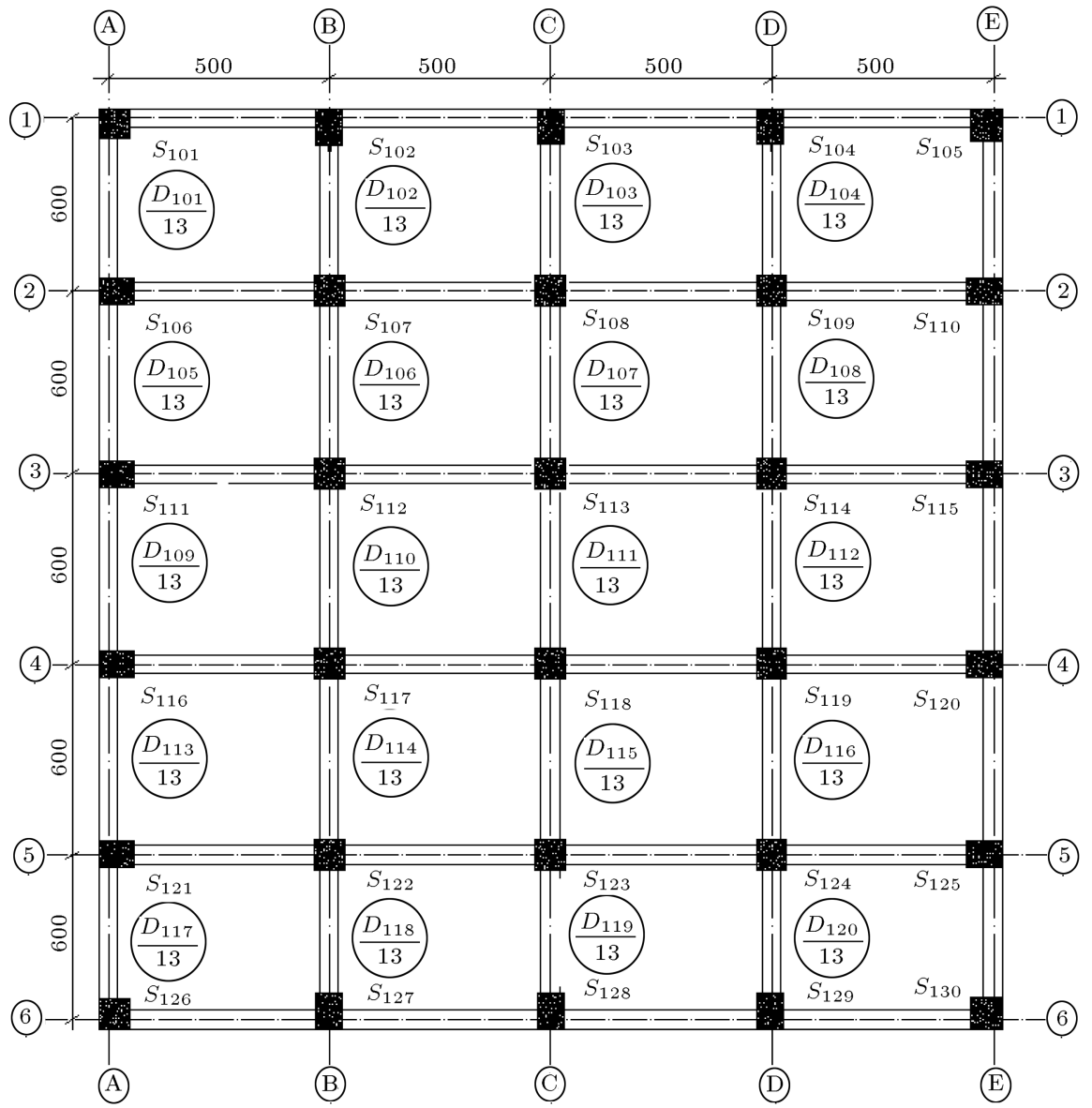

Figure 1. Plan of buildings.

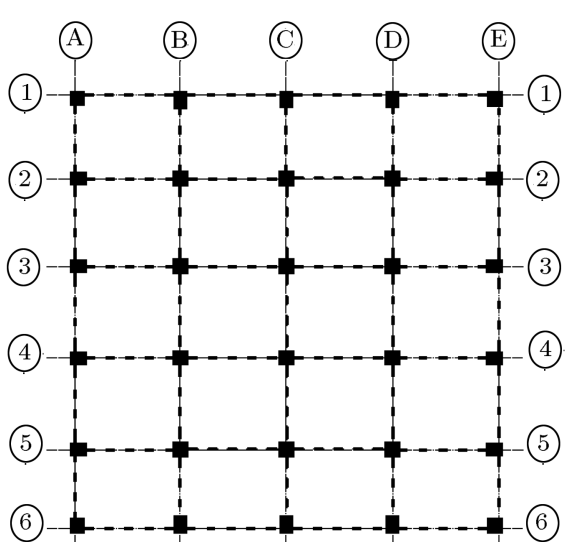

(A) (B)
(C) (D)

(E)
(A)

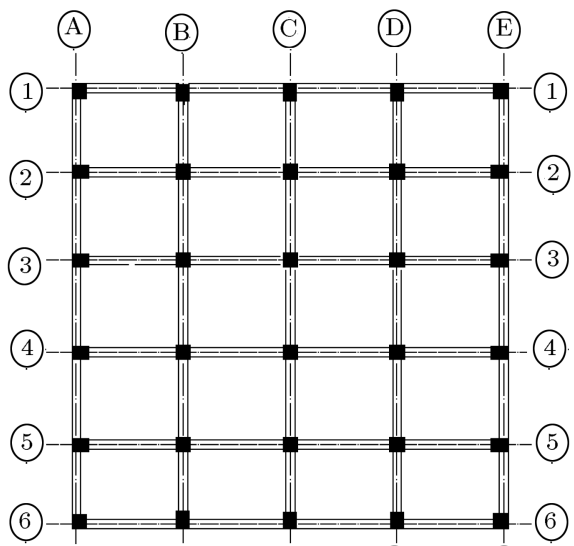

(A) (B)

(B)
(C)

(D)
(E)

Figure 2. Location of the infill walls.

Buildings were modelled by SAP 2000 [34] software program, and all the possible combinations of building height, $E$ and $t$ were considered to estimate the vibration periods of the buildings. With 9 different building heights, 6 different elasticity moduli of infill walls, and 5 different infill wall thicknesses, 270 different buildings were modelled and fundamental periods of the buildings were determined. It is assumed that all the spans have infill walls without openings, and this assumption is depicted in Figure 2. Koçak et al. [35] investigated the absence of infill walls in base storeys of $3,6,9$, and 11 storey buildings, and showed that fundamental vibration period of buildings with the absence of infills in base storey is close to the corresponding building fully infilled. However, they concluded that relative displacement and irregularity 
are affected by the absence of infills in base storey, contrary to fundamental vibration period. So, the absence of infills in base storey is not considered in this study in terms of period.

\section{Results of analyses}

Analyses were conducted using SAP 2000 [34], and the first-mode periods of all buildings were determined. Effects of elasticity modulus of infill walls and wall thickness were investigated.

\subsection{Effect of elasticity modulus of infill walls on structural period}

Elasticity modulus of infill walls was taken as changing values between 2500-7800 $\mathrm{MPa}$ (2500, 3500, 4200, $4600,6000,7800)$ to investigate the effect of elasticity modulus on the fundamental period of structures. Figure 3 shows the results of analyses for different elasticity moduli, and period plots are given for infill wall thicknesses, $t=100 \mathrm{~mm}$ and $t=300 \mathrm{~mm}$, which are lower and upper values of infill wall thickness, respectively. Plots for other infill wall thickness are not given for the space limitation.

It is clear from Figure 3 and through basic knowledge that period decreases while elasticity modulus increases. Rate of the effect of the elasticity modulus of the infill wall on structural fundamental period is almost constant with the changing of infill wall thickness.

\subsection{Effect of infill wall thickness on structural period}

$t=100,150,200,250,300 \mathrm{~mm}$ were taken into account to investigate the effect of infill wall thickness

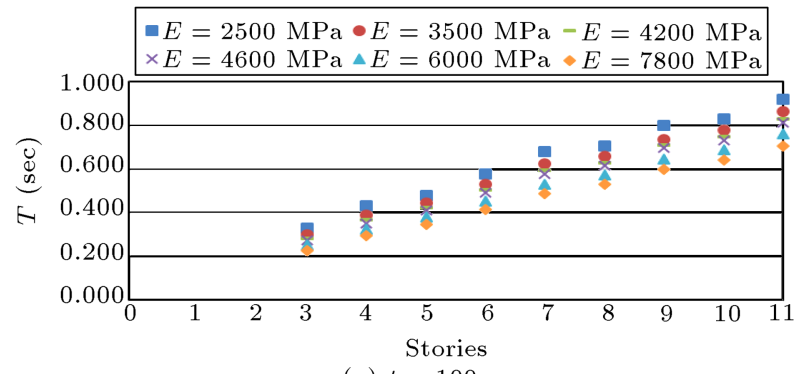

(a) $t=100 \mathrm{~mm}$

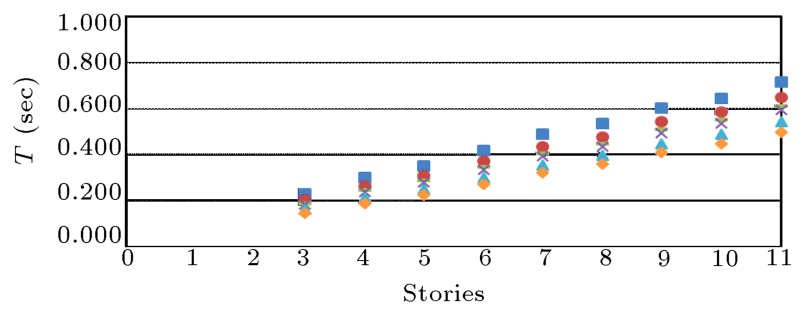

(b) $t=300 \mathrm{~mm}$

Figure 3. Effect of elasticity modulus on fundamental period for constant infill wall thickness.

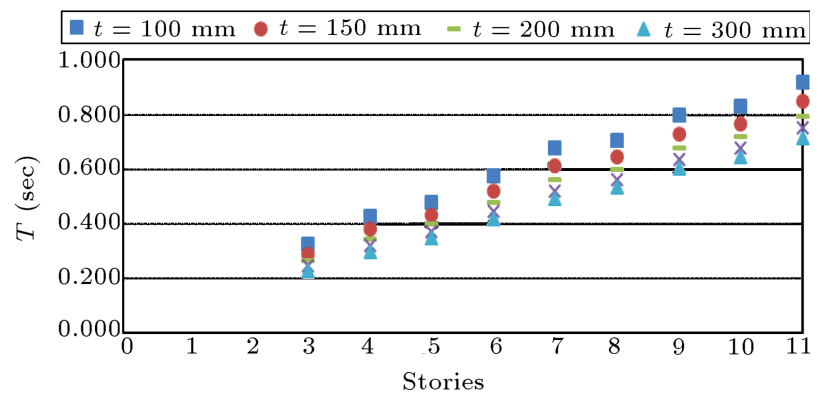

(a) $E=2500 \mathrm{MPa}$

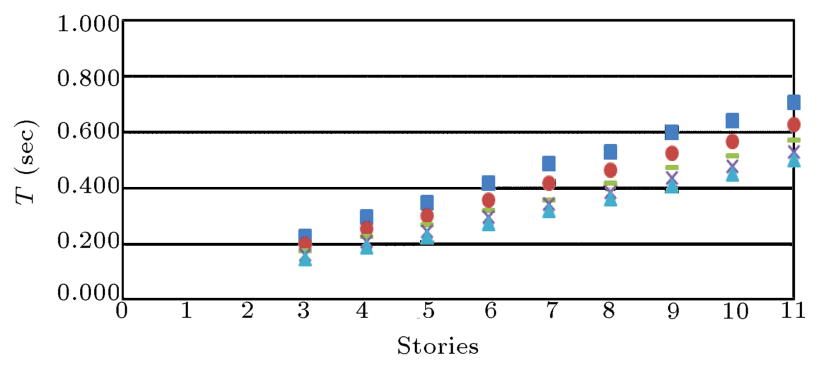

(b) $E=7800 \mathrm{MPa}$

Figure 4. Effect of infill wall thickness on fundamental period for constant infill wall elasticity modulus.

on structural fundamental period. Effect of infill wall thickness on the period for elasticity modulus of constant infill wall is depicted in Figure 4. This figure is plotted only for $E=2500 \mathrm{MPa}$ and $E=7800 \mathrm{MPa}$. Results of other elasticity moduli were not given due to space limitation. According to the results, the period decreases, while infill wall thickness increases; however, the decreasing rate of the period is almost constant with the change of elasticity modulus.

\section{Regression analysis}

Nonlinear regression analyses were carried out to obtain an appropriate equation to represent structural fundamental vibration period as a function of $H, E$, and $t$. Nonlinear regression analyses were conducted to derive a simplified equation using the LevenbergMarquardt method in the regression module of STATISTICA [36]. The proposed equation is expressed as follows:

$$
T_{d}=\frac{x_{1} H^{x_{2}}}{E^{x_{3}} t^{x_{4}}},
$$

$H$ is in "m", $E$ is in "MPA", and $t$ is in "mm" for the proposed equation. $x_{1}, x_{2}, x_{3}$, and $x_{4}$ are constants given in Table 2. It is clear from Table 2 that the equation has good correlation coefficient, meaning that the proposed equation gives good fit with the observed values of period. Figure 5 shows the dispersion of the regressed function of period; $T_{\text {obtained }}$ is the period obtained via numerical analysis, and $T_{\text {predicted }}$ is the period obtained by Eq. (2). It is seen from Figure 5 that 
Table 2. Coefficients of Eq. (2) and correlation coefficient.

\begin{tabular}{ccccc}
\hline $\boldsymbol{x}_{\boldsymbol{1}}$ & $\boldsymbol{x}_{\boldsymbol{2}}$ & $\boldsymbol{x}_{\boldsymbol{3}}$ & $\boldsymbol{x}_{\boldsymbol{4}}$ & $\begin{array}{c}\text { Correlation } \\
\text { coefficient }\end{array}$ \\
\hline 2.005195 & 0.858439 & 0.301073 & 0.297021 & 0.995 \\
\hline
\end{tabular}

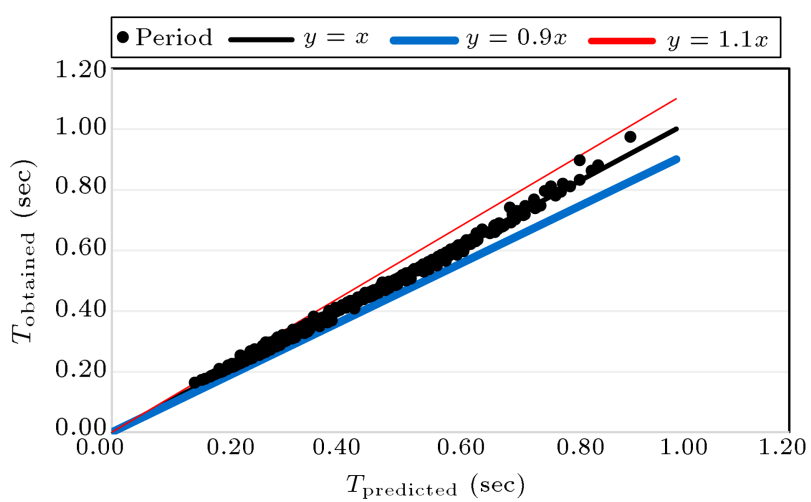

Figure 5. Dispersion of the proposed equation (observed and predicted values of period).

the proposed equation provides a good approximation of the period. According to Figure 5, dispersion of the equation is between $\pm \% 10$, and it can be said that the equation presents sufficient results.

\section{Comparisons of the proposed equations}

First of all, comparisons were conducted between periods of hypothetic buildings considered in this study and the equations proposed by previous studies. TSC 1998 [37] proposed Eq. (3) and UBC [28] proposed Eq. (4) to estimate fundamental vibration period of a building:

$$
\begin{aligned}
& T_{d}=C_{t} H^{3 / 4}, \\
& T_{d}=C_{t} h_{n}^{3 / 4} .
\end{aligned}
$$

TSC 1998 [37] suggested 0.07 and UBC [28] suggested 0.0731 for $C_{t}$ of RC frame buildings.

Guler et al. [22] proposed Eq. (5) to estimate fundamental vibration period of a building considering infill wall effect. They assumed that $E=6000 \mathrm{MPA}$ and $t=150 \mathrm{~mm}$.

$$
T_{d}=0.026 H^{0.9}
$$

Goel and Chopra [12] proposed Eqs. (6) and (7) as lower and upper limits of period, respectively:

$$
\begin{aligned}
& T_{L d}=0.047 H^{0.9}, \\
& T_{U d}=0.067 H^{0.9} .
\end{aligned}
$$

Koçak and Yildirim [31] proposed Eq. (8) for fundamental vibration period considering infill wall effect:

$$
\begin{aligned}
& T_{d}=T_{c}\left(1-\frac{\Delta T}{100}\right), \\
& \Delta T(\%)=69.1 x A_{k}^{1.08} .
\end{aligned}
$$

$A_{k}$ is wall area/[structural element (column area) + wall area], and $T_{c}$ is period of bare frame building. Koçak and Yildirim [31] assumed that $E=6000 \mathrm{MPa}$ and $t=150 \mathrm{~mm}$ for infill wall.

The considered buildings' periods and period of previously given equations are given in Table 3 , and some comparisons were drawn. 18 randomly selected buildings are given in Table 3 due to space limitation. It is clear from Table 3 that the equation proposed by Guler et al. [22] gives more accurate results than other equations.

In Table 4, measured periods of 9 existing buildings are given, and the theoretical estimation of periods with the proposed equations was done. According to Table 4, the proposed equation in this study gives very good estimations and presents more approximate results to period of the existing buildings than the equations of previous studies.

\section{Conclusions}

In this study, effects of elasticity modulus of infill wall and thickness of infill wall on fundamental vibration period of a building were investigated, and also a new equation was proposed as a function of building height, elasticity modulus, and thickness to estimate fundamental vibration period. An extensive statistical study was conducted to estimate the equation through nonlinear regression analysis. The following conclusions can be drawn:

- According to the results of this study, infill wall has considerable effect on fundamental vibration period which confirms the results of previous studies;

- Increasing elasticity modulus of infill wall and also increasing thickness of infill wall increase the stiffness of a building, and so decrease vibration period. As a result of this relationship, infill walls and their elasticity moduli and thicknesses should be taken into account in the estimation of vibration period;

- An equation is proposed in this study for the estimation of vibration period, and it can be said 
Table 3. Comparison of period of the considered buildings and the proposed equations.

\begin{tabular}{|c|c|c|c|c|c|c|c|c|c|c|}
\hline \multirow[b]{2}{*}{$\begin{array}{l}\text { Height } \\
\qquad(\mathrm{m})\end{array}$} & \multirow[b]{2}{*}{$\begin{array}{c}E \\
(\mathrm{MPa})\end{array}$} & \multirow[b]{2}{*}{$\begin{array}{c}t \\
(\mathrm{~mm})\end{array}$} & \multicolumn{8}{|c|}{$T(\mathrm{sec})$} \\
\hline & & & $\begin{array}{c}T_{\text {building }} \\
\text { with } \\
\text { infill wall }\end{array}$ & $\begin{array}{c}T_{\text {building }} \\
\text { without } \\
\text { infill wall }\end{array}$ & $\begin{array}{c}\text { Guler } \\
\text { et al. } \\
(2008)\end{array}$ & $\begin{array}{l}\text { TSC } \\
1998\end{array}$ & $\begin{array}{c}\text { Goel and } \\
\text { Chopra } \\
\text { (lower) }\end{array}$ & $\begin{array}{c}\text { Goel and } \\
\text { Chopra } \\
\text { (upper) }\end{array}$ & $\begin{array}{c}\text { Koçak and } \\
\text { Yildirim (2011) }\end{array}$ & $\begin{array}{l}\text { UBC } \\
1997\end{array}$ \\
\hline 9 & 2500 & 100 & 0.327 & & 0.188 & 0.364 & 0.340 & 0.484 & 0.211 & 0.380 \\
\hline 9 & 4200 & 150 & 0.295 & 0.476 & 0.188 & 0.364 & 0.340 & 0.484 & 0.193 & 0.380 \\
\hline 9 & 6000 & 200 & 0.194 & & 0.188 & 0.364 & 0.340 & 0.484 & 0.171 & 0.380 \\
\hline 12 & 2500 & 100 & 0.430 & & 0.243 & 0.451 & 0.440 & 0.627 & 0.284 & 0.471 \\
\hline 12 & 4200 & 150 & 0.320 & 0.640 & 0.243 & 0.451 & 0.440 & 0.627 & 0.260 & 0.471 \\
\hline 12 & 6000 & 200 & 0.252 & & 0.243 & 0.451 & 0.440 & 0.627 & 0.246 & 0.471 \\
\hline 15 & 2500 & 100 & 0.480 & & 0.297 & 0.534 & 0.538 & 0.767 & 0.288 & 0.557 \\
\hline 15 & 4200 & 150 & 0.372 & 0.652 & 0.297 & 0.534 & 0.538 & 0.767 & 0.264 & 0.557 \\
\hline 15 & 6000 & 200 & 0.296 & & 0.297 & 0.534 & 0.538 & 0.767 & 0.250 & 0.557 \\
\hline 18 & 2500 & 100 & 0.578 & & 0.351 & 0.612 & 0.634 & 0.903 & 0.353 & 0.639 \\
\hline 18 & 4200 & 150 & 0.446 & 0.798 & 0.351 & 0.612 & 0.634 & 0.903 & 0.324 & 0.639 \\
\hline 18 & 6000 & 200 & 0.355 & & 0.351 & 0.612 & 0.634 & 0.903 & 0.306 & 0.639 \\
\hline 21 & 2500 & 100 & 0.679 & & 0.403 & 0.687 & 0.728 & 1.038 & 0.391 & 0.717 \\
\hline 21 & 4200 & 150 & 0.521 & 0.850 & 0.403 & 0.687 & 0.728 & 1.038 & 0.358 & 0.717 \\
\hline 21 & 6000 & 200 & 0.415 & & 0.403 & 0.687 & 0.728 & 1.038 & 0.338 & 0.717 \\
\hline 24 & 2500 & 100 & 0.705 & & 0.454 & 0.759 & 0.821 & 1.170 & 0.402 & 0.793 \\
\hline 24 & 4200 & 150 & 0.563 & 0.908 & 0.454 & 0.759 & 0.821 & 1.170 & 0.368 & 0.793 \\
\hline 24 & 6000 & 200 & 0.458 & & 0.454 & 0.759 & 0.821 & 1.170 & 0.348 & 0.793 \\
\hline 27 & 2500 & 100 & 0.799 & & 0.505 & 0.829 & 0.913 & 1.301 & 0.459 & 0.866 \\
\hline 27 & 4200 & 150 & 0.636 & 1.037 & 0.505 & 0.829 & 0.913 & 1.301 & 0.420 & 0.866 \\
\hline 27 & 6000 & 200 & 0.480 & & 0.505 & 0.829 & 0.913 & 1.301 & 0.398 & 0.866 \\
\hline 30 & 2500 & 100 & 0.829 & & 0.555 & 0.897 & 1.003 & 1.430 & 0.517 & 0.937 \\
\hline 30 & 4200 & 150 & 0.677 & 1.151 & 0.555 & 0.897 & 1.003 & 1.430 & 0.474 & 0.937 \\
\hline 30 & 6000 & 200 & 0.561 & & 0.555 & 0.897 & 1.003 & 1.430 & 0.448 & 0.937 \\
\hline 33 & 2500 & 100 & 0.919 & & 0.605 & 0.964 & 1.093 & 1.559 & 0.531 & 1.006 \\
\hline 33 & 4200 & 150 & 0.750 & 1.170 & 0.605 & 0.964 & 1.093 & 1.559 & 0.487 & 1.006 \\
\hline 33 & 6000 & 200 & 0.621 & & 0.605 & 0.964 & 1.093 & 1.559 & 0.460 & 1.006 \\
\hline
\end{tabular}


Table 4. Comparisons of the measured period of existing buildings and the proposed equations.

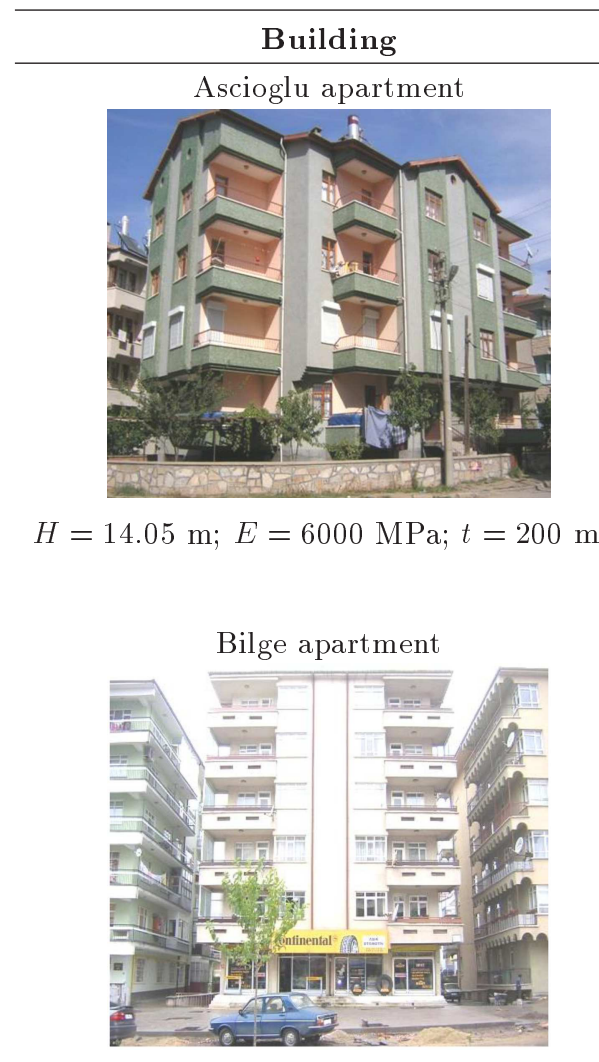

$H=17.80 \mathrm{~m} ; E=6000 \mathrm{MPa} ; t=200 \mathrm{~mm}$

Enver Parlak apartment

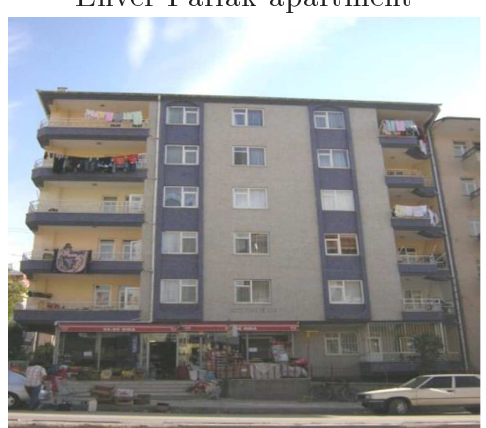

$H=17.10 \mathrm{~m} ; E=6000 \mathrm{MPa} ; t=200 \mathrm{~mm}$

Kocyiğit apartment

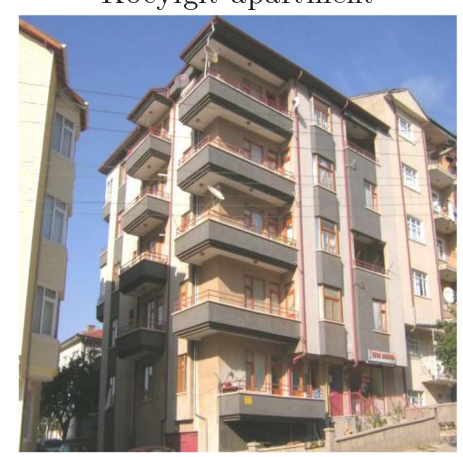

$H=17.50 \mathrm{~m} ; E=6000 \mathrm{MPa} ; t=200 \mathrm{~mm}$
Method of estimated periods
Measured value

Kocak \& Yildirim (2011)

Guler et al. (2008)

TSC 1998

UBC 1997

Goel and Chopra

Equation proposed in this study

Measured value

Kocak \& Yildirim (2011)

Guler et al. (2008)

TSC 1998

UBC 1997

Goel and Chopra

Equation proposed in this study

Measured value

Kocak \& Yildirim (2011)

Guler et al. (2008)

TSC 1998

UBC 1997

Goel and Chopra

Equation proposed in this study

Measured value

Kocak \& Yildirim (2011)

Guler et al. (2008)

TSC 1998

UBC 1997

Goel and Chopra

Equation proposed in this study

\subsection{6}

$T_{d}=T_{c} \cdot\left(1-k_{E} \cdot A k^{1.08} / 100\right)$ $k_{E}=69.10$

0.324

$$
T_{d}=1.75\left(0.026 H^{0.9}\right)
$$

0.607

$T_{d}=C_{t} H^{3 / 4}$

0.606

$T_{d}=C_{t}\left(h_{N}\right)^{3 / 4}$

0.633

$T_{L C}=0.047 H^{0.9}$

0.627

$T_{U C}=0.067 H^{0.9}$

0.894

$T_{d}=\frac{x_{1} H^{x_{2}}}{E^{x} 3 t^{x_{4}}}$

0.359

0.295 $T_{d}=T_{c} \cdot\left(1-k_{E} \cdot A k^{1.08} / 100\right)$
$k_{E}=69.10$

0.296

$$
T_{d}=1.75\left(0.026 H^{0.9}\right)
$$

0.585

$T_{d}=C_{t} H^{3 / 4}$

0.588

$T_{d}=C_{t}\left(h_{N}\right)^{3 / 4}$

0.614

$T_{L C}=0.047 H^{0.9}$

0.605

$T_{U C}=0.067 H^{0.9}$

0.862

$T_{d}=\frac{x_{1} H^{x_{2}}}{E^{x_{3}} t^{x_{4}}}$

0.346
0.314

$$
\begin{gathered}
T_{d}=T_{c} \cdot\left(1-k_{E} \cdot A k^{1.08} / 100\right) \\
k_{E}=69.10
\end{gathered}
$$$$
T_{d}=1.75\left(0.026 H^{0.9}\right)
$$

$T_{d}=C_{t} H^{3 / 4}$

$T_{d}=C_{t}\left(h_{N}\right)^{3 / 4}$

$T_{L C}=0.047 H^{0.9}$

0.624

$T_{U C}=0.067 H^{0.9}$

0.617

0.880

$T_{d}=\frac{x_{1} H^{x_{2}}}{E^{x} 3 t^{x} 4}$

0.353 
Table 4. Comparisons of the measured period of existing buildings and the proposed equations (continued).

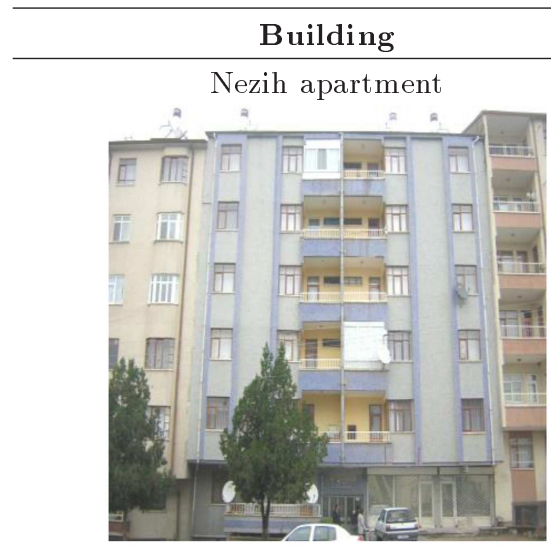

$H=21.15 \mathrm{~m} ; E=6000 \mathrm{MPa} ; t=150 \mathrm{~mm}$

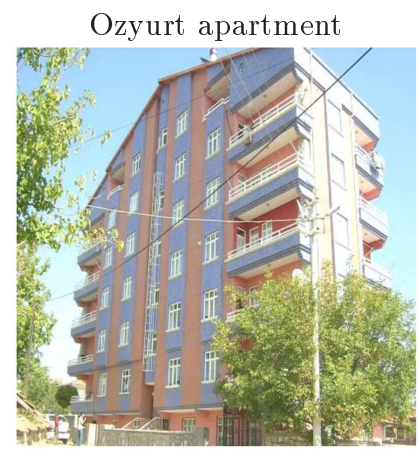

$H=20.40 \mathrm{~m} ; E=6000 \mathrm{MPa} ; t=200 \mathrm{~mm}$

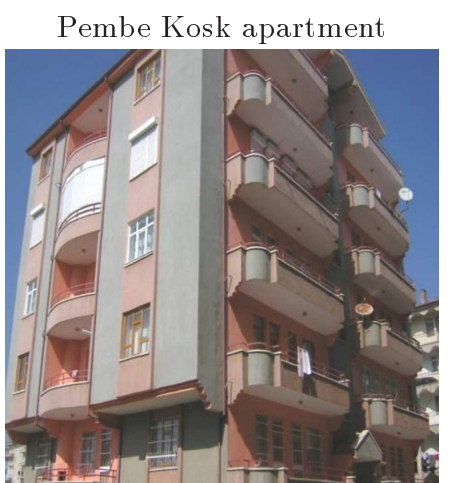

$H=17.70 \mathrm{~m} ; E=6000 \mathrm{MPa} ; t=150 \mathrm{~mm}$

\section{Sahiner apartment}

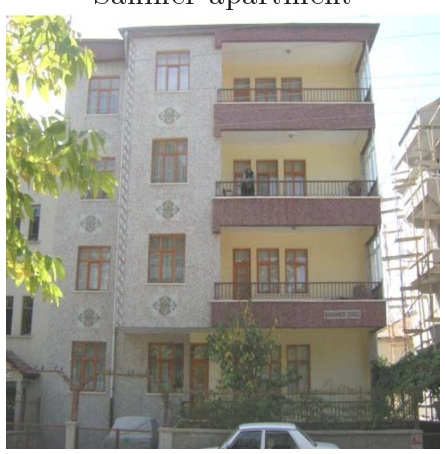

Measured value

Kocak \& Yildirim (2011)

Guler et al. (2008)

TSC 1998

UBC 1997

Goel and Chopra

Equation proposed in this study

Measured value

Kocak \& Yildirim (2011)

Guler et al. (2008)

TSC 1998

UBC 1997

Goel and Chopra

Equation proposed in this study

Measured value

Kocak \& Yildirim (2011)

Guler et al. (2008)

TSC 1998

UBC 1997

Goel and Chopra

Equation proposed in this study

$$
\begin{gathered}
T_{d}=T_{c} \cdot\left(1-k_{E} \cdot A k^{1.08} / 100\right) \\
k_{E}=69.10 \\
T_{d}=1.75\left(0.026 H^{0.9}\right) \\
T_{d}=C_{t} H^{3 / 4} \\
T_{d}=C_{t}\left(h_{N}\right)^{3 / 4} \\
T_{L C}=0.047 H^{0.9} \\
T_{U C}=0.067 H^{0.9} \\
T_{d}=\frac{x_{1} H^{x_{2}}}{E^{x} 3 t^{x_{4}}}
\end{gathered}
$$

0.330

0.686

0.672

0.701

0.709

1.010

0.403

0.396

0.412

0.604

0.604

0.631

0.624

0.889

0.389

$H=15.75 \mathrm{~m} ; E=6000 \mathrm{MPa} ; t=150 \mathrm{~mm}$ 
Table 4. Comparisons of the measured period of existing buildings and the proposed equations (continued).

\begin{tabular}{|c|c|c|c|}
\hline Building & Method of estimated periods & Proposed equations & $T_{d}(\mathrm{sec})$ \\
\hline Tolgahan apartment & Measured value & & 0.342 \\
\hline & Kocak \& Yildirim (2011) & $\begin{array}{c}T_{d}=T_{c} \cdot\left(1-k_{E} \cdot A k^{1.08} / 100\right) \\
k_{E}=69.10\end{array}$ & 0.333 \\
\hline & Guler et al. (2008) & $T_{d}=1.75\left(0.026 H^{0.9}\right)$ & 0.497 \\
\hline II & TSC 1998 & $T_{d}=C_{t} H^{3 / 4}$ & 0.513 \\
\hline -11回 11 & UBC 1997 & $T_{d}=C_{t}\left(h_{N}\right)^{3 / 4}$ & 0.536 \\
\hline & Goel and Chopra & $T_{L C}=0.047 H^{0.9}$ & 0.513 \\
\hline & & $T_{U C}=0.067 H^{0.9}$ & 0.732 \\
\hline 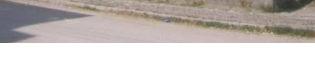 & Equation proposed in this study & $T_{d}=\frac{x_{1} H^{x_{2}}}{E^{x_{3}} t^{x_{4}}}$ & 0.323 \\
\hline
\end{tabular}

$H=14.25 \mathrm{~m} ; E=6000 \mathrm{MPa} ; t=150 \mathrm{~mm}$

that proposed equation gives very good estimations when infill wall effect is considered in the estimation of fundamental vibration period.

\section{References}

1. FEMA 356, Pre-Standard and Commentary for the Seismic Rehabilitation of Buildings, Federal Emergency Management Agency, Washington DC (2000).

2. Su, R.K.L., Lee, C.L. and Wang, Y.P. "Seismic spectral acceleration assessment of masonry infilled reinforced concrete buildings by a coefficientbased method", Structural Engineering and Mechanics, 41(4), pp. 479-494 (2012).

3. Furtado, A., Rodrigues, H. and Arêde, A. "Modelling of masonry infill walls participation in the seismic behavior of RC buildings using openSees", International Journal of Advanced Structural Engineering, 7(2), pp. 117-127 (2015).

4. Rodrigues, H., Varum, H. and Costa, A. "Simplified macro-model for infill masonry panels", Journal of Earthquake Engineering, 14(3), pp. 390-416 (2010).

5. Smyrou, E., Blandon, C., Antoniou, S., Pinho, R. and Crisafulli, F., "Implementation and verification of a masonry panel model for nonlinear dynamic analysis of infilled RC frames", Bulletin Earthquake Engineering, 9(6), pp. 1519-1534 (2011).

6. Cavaleri, L., Fossetti, M. and Papia, M. "Infilled frames: developments in the evaluation of cyclic behaviour under lateral loads", Structural Engineering and Mechanics, 21(4), pp. 469-494 (2005).

7. Hatzigeorgiou, G.D. and Kanapitsas, G. "Evaluation of fundamental period of low-rise and mid-rise reinforced concrete buildings", Earthquake Engineering and Structural Dynamics, 42(11), pp. 1599-1616 (2013).

8. Papia, M., Cavaleri, L. and Fossetti, M. "Infilled frames: developments in the evaluation of the stiffening effect of infills", Structural Engineering and Mechanics, 16(6), pp. 675-693 (2003).
9. Asteris, P.G., Trapani, F.D. and Cavaleri, L. "Parameters affecting the fundamental period of infilled RC frame structures", Earthquakes and Structures, 9(5), pp. 999-1028 (2015).

10. Fiorato, A.E., Sozen, M.A. and Gamble, W.L., An Investigation of the Interaction of Reinforced Concrete Frames with Masonry Filler Walls, Report No. UILUENG 70-100, University of Illinoi, Urbana-Champaign, IL (1970).

11. Zarnic, R. and Tomazevic, M. "An experimentally obtained method for evaluation of the behaviour of masonry infilled RC frames", Proceedings of the 9th World Conference on Earthquake Engineering, Kyoto (1998).

12. Goel, R.K. and Chopra, A.K. "Period formulas for moment-resisting frame buildings", Journal of Structural Engineering, 123(11), pp. 1454-1461 (1997).

13. Goel, R.K. and Chopra, A.K. "Period formulas for concrete shear wall buildings", Journal of Structural Engineering, 124(4), pp. 426-433 (1998).

14. Chopra, A.K. and Goel, R.K. "Building period formulas for estimating seismic displacements", Earthquake Spectra, 16(2), pp. 533-536 (2000).

15. Panagiotakos, T.B. and Fardis, M.N. "Deformationcontrolled earthquake resistant design of RC buildings", Journal of Earthquake Engineering, 3(4), pp. 495-518 (1999).

16. Al-Chaar, G.K. and Lamb, G.E., Design of FiberReinforced Polymer Materials for Seismic Rehabilitation of Infilled Concrete Structures, US Army Corps of Engineers, Engineer Research and Development Center, ERDC/CERL TR-02-33 (2002).

17. Amanat, K.M. and Hogue, E. "A rationale for determining the natural period of RC buildings frames having infill", Engineering Structures, 28(4), pp. 495$502(2006)$.

18. Celep, Z. and Gencoglu, M. "Effect of the infill walls on the behaviour of the concrete structures of frame type subjected to earthquake loading", 5th National Conference on Earthquake Engineering, Istanbul (2003). 
19. Crowley, H. and Pinho, R. "Period-height relationship for existing European reinforced concrete buildings", Journal of Earthquake Engineering, 8(S.I.1), pp. 93119 (2004).

20. Budak, A. "Effect of the infill walls on the building earthquake loads", rth International Congress on Advances in Civil Engineering, Istanbul (2006).

21. Guler, H., Yuksel, E., Celik, M. and Altan, M. "Fundamental periods of RC framed buildings having infill walls", 7th International Congress on Advances in Civil Engineering, Istanbul (2006).

22. Guler, H., Yuksel, E. and Kocak, A. "Estimation of the fundamental vibration period of existing RC buildings in Turkey", Utilizing Ambient Vibration Records, Journal of Earthquake Engineering, 12(S2), pp. 140150 (2008).

23. Oliveira, C.S. and Navarro, M. "Fundamental periods of vibration of $\mathrm{RC}$ buildings in Portugal from insitu experimental and numerical techniques", Bulletin Earthquake Engineering, 8, pp. 609-642 (2010).

24. Panzera, F., Lombardo, G. and Muzzetta, I. "Evaluation of building dynamic properties through in situ experimental techniques and 1D modeling: the example of Catania Italy", Physics and Chemistry of the Earth, 63, pp. 136-146 (2013).

25. Ditommasso, R., Vona, M., Gallipoli, M.R. and Mucciarelli, M. "Evaluation and considerations about fundamental periods of damaged reinforced concrete buildings", Natural Hazards and Earth System Sciences, 13(7), pp. 1903-1912 (2013).

26. Pan, T.C., Goh, K.S. and Megawati, K. "Empirical relationships between natural vibration period and height of a buildings in Singapore", Earthquake Engineering and Structural Dynamics, 43(3), pp. 449-465 (2014).

27. NEHRP, NEHRP Recommended Provisions for Seismic Regulations for New Buildings, Building Seismic Safety Council, Washington DC (1994).

28. UBC, Uniform Building Code, Structural Design Requirements (1997).

29. EC8, Eurocode 8, Design of Structures for Earthquake Resistance, European Standard, prEn 1998-1 (2003).

30. TSC 2007, Turkish Code for Buildings in Seismic Zones, The Ministry of Public Works and Settlement, Ankara, Turkey (2007).

31. Koçak, A. and Yildirim, M.K. "Effects of infill wall ratio on the period of reinforced concrete framed buildings", Advances in Structural Engineering, 14(5), pp. 731-743 (2011).
32. Polyakov, S.V., On the Interaction Between Masonry Filler Walls and Enclosing Frame When Loaded in the Plane of the Wall, Earthquake Engineering Research Institute (EERI), San Francisco, pp. 36-42 (1960).

33. Ersin, U.D. "Tiny vibration measurements and integration of infill walls to the mechanical model", MSC Thesis, Istanbul Technical University, Istanbul, Turkey (1997).

34. SAP 2000, Computers and Structure Inc., Ver: 14.2.2 (2010).

35. Kocak, A., Zengin, B., Eyyubov, C. and Toydemir, B. "Effect of the infill wall irregularities in basement to structure behavior in RC buildings", ScientificTechnical Progress in Construction and Architecture, Baku (2014).

36. STATISTICA, StatSoft Inc., www.statsoft.com (2001).

37. TSC 1998, Turkish Code for Buildings in Seismic Zones, The Ministry of Public Works and Settlement, Ankara, Turkey, (1998).

\section{Biographies}

Ali Koçak is an Associate Professor in Structural Engineering Division, Department of Civil Engineering, Yildiz Technical University, Turkey. He teaches Structural Analysis and Earthquake Engineering courses at undergraduate and graduate levels. He studies earthquake engineering, finite-element methods, performance-based design, masonry buildings, and advanced structural analysis.

Muzaffer Borekci obtained BSc, MSc, and PhD degrees in Yildiz Technical University, Istanbul, Turkey. His main areas of research interests are earthquake engineering, performance-based design, earthquakeresistant design of structures, seismic reliability of structures, and rehabilitation of RC structures. He still works as a Research Assistant in Structural Engineering Division, Department of Civil Engineering, Yildiz Technical University.

Basak Zengin obtained her MSc degree from Suleyman Demirel University in Turkey. She still continues PhD studies in Yildiz Technical University, and scope of her $\mathrm{PhD}$ research covers experimental and theoretical modelling of masonry buildings. Her research area is construction materials and design of RC structures. 